\title{
O CASO SIMULADO CTS NA FORMAÇÃO INICIAL DE PROFESSORES DE QUÍMICA: UM ESTUDO DO ROMPIMENTO DA BARRAGEM EM BRUMADINHO-MG
}

\section{THE STS SIMULATED CASE IN THE INITIAL FORMATION OF CHEMISTRY TEACHERS: A STUDY OF THE DAM RUPTURE IN BRUMADINHO-MG}

\author{
CABRAL, Wallace Alves ${ }^{1}$
}

\begin{abstract}
RESUMO
Esse artigo objetiva investigar algumas dificuldades e potencialidades encontrados por licenciandos em Química ao vivenciarem a construção e a execução de um caso simulado. Tendo como lentes a perspectiva Ciência, Tecnologia e Sociedade e a Análise de Discurso de Linha Francesa, foi discutido o rompimento da barragem de rejeitos de minério em Brumadinho - MG. A atividade foi organizada em três etapas: construção, execução e avaliação. A partir da personificação dos atores em cada grupo envolvido na problemática (Mineradora, Ambientalistas, ONG e Governo), os acadêmicos vivenciaram o caso simulado. A partir da transcrição da discussão ocorrida na etapa de avaliação, o corpus de análise foi construído. As análises mostraram que a vivência no caso simulado fomentaram processos argumentativos, contribuindo para uma posição mais coerente ao levar em conta outros pontos de vista. Apesar da limitação do tempo de execução do caso simulado, essa atividade propiciou discussões para além da sala de aula.
\end{abstract}

PaLAVRAS-ChaVe: Química; Formação de professores; Caso simulado; AD; CTS.

\begin{abstract}
This paper aims to investigate some difficulties and potentialities encountered by chemistry undergraduates when experiencing the construction and execution of a simulated case. Taking as perspective Science, Technology and Society as well as the French Line Discourse Analysis, the rupture of the ore tailings dam in Brumadinho, Minas Gerais was discussed. The activity was organized in three stages: construction, execution and evaluation. From the personification of the actors in each group involved in the problem (Mining, Environmentalists, NGOs and Government), the students experienced the simulated case. From the transcript of the discussion that occurred in the evaluation stage, the corpus of analysis was built. The analyzes showed that the experience in the simulated case fostered argumentative processes, contributing to a more coherent position by
\end{abstract}

1 Universidade Federal de São João del-Rei - UFSJ / Departamento de Ciências Naturais. São João del-Rei, MG, Brasil. ORCID: https://orcid.org/0000-0002-4685-7486 e-mail: wallaceacabral@gmail.com 
DOI: $10.12957 / \mathrm{e}-\mathrm{mosaicos} .2021 .45864$

taking into account other points of view. Despite the limited execution time of the simulated case, this activity provided discussions beyond the classroom.

KeYworDS: Chemistry; Teacher training; Case simulated; DA; STS.

\section{AS ATIVIDADES MINERADORAS NO BRASIL A PARTIR DAS LENTES DAS PERSPECTIVAS CTS E AD}

"Quando se falou em mineração, a primeira referência define-se no estado de Minas Gerais, onde tudo se passou, na vivência do drama que se descreveu".

(Olintho Pereira da Silva)

É notória, no cenário brasileiro, a proporção que as atividades mineradoras têm ganhado no meio midiático, tendo notícias relacionadas aos impactos econômicos, ambientais, sociais e culturais. Tais atividades são uma das principais do estado de Minas Gerais (MG) e do Brasil, gerando emprego e renda para as comunidades locais e arrecadação para o país.

Mais recentemente, as cidades de Mariana e Brumadinho se tornaram notícias, após o rompimento de barragens de rejeitos. Conforme discute Passos, Coelho e Dias (2017), o modelo de exploração implementado é reflexo da dinâmica capitalista, gerando consequências em diferentes esferas, muitas vezes, irrecuperáveis. Por exemplo,

Os impactos ao meio ambiente estão relacionados à expansão ilimitada da extração dos recursos naturais, ao alagamento de extensas áreas verdes e ao desequilíbrio da fauna, dentre outros; enquanto os impactos sociais incluem, frequentemente, a precarização da força de trabalho, o aumento dos casos de violência urbana e a transformação arbitrária de dinâmicas socioespaciais construídas historicamente (PASSOS, COELHO; DIAS, p. 270).

Resolver esses entraves não é tarefa simples, pois relações de poder (ORLANDI, 2012) são estabelecidas, principalmente, entre mineração e município, aprofundando a dominação do capital na gestão e no planejamento das cidades brasileiras. 
DOI: $10.12957 / \mathrm{e}-\mathrm{mosaicos} .2021 .45864$

Como cidadãos, não podemos assumir uma posição polarizada frente ás minerações, sendo essas de grande importância para a "evolução social de um país, e de seu povo". Assim, é preciso convergir as forças rumo a um desenvolvimento sustentável, tentando aliar o desenvolvimento econômico à preservação e à conservação do meio ambiente, bem como de suas derivações sociais" (LANA, 2015, p. 46).

Pensando no contexto em que estudantes, professores e comunidade interagem, é possível perceber o papel das escolas e das universidades frente a esses problemas, não os desconsiderando e tampouco apresentando um olhar ingênuo. Partindo do pressuposto que a decisão é do indivíduo imerso na sociedade, cabem (não só) às instituições de ensino auxiliá-lo, apontando os critérios positivos e negativos do juízo. Portanto, temas sociocientíficos devem adentrar nos espaços institucionalizados de ensino e, ao mesmo tempo, retornar para a sociedade com potencial de tomada de decisão ${ }^{2}$ pelos sujeitos envolvidos.

As Instituições de Ensino que visam à formação de cidadãos têm um papel importante de não só trazer informações, mas também um conhecimento embasado que possibilite aos estudantes a compreensão do universo a sua volta. É, portanto, imprescindível o debate pela comunidade acadêmica e escolar de maneira a fomentar o pensamento crítico dos alunos em torno do tema (SANTOS; MORTIMER, 2001).

Para o desenvolvimento de temas sociocientíficos rumo à tomada de decisão, é importante que os estudantes discutam problemas do seu dia a dia. "A abordagem de temas locais, vinculados à comunidade dos estudantes, torna a discussão mais próxima. Ao discutir questões relacionadas a sua vida, os alunos terão oportunidade de confrontar os diferentes valores da própria turma". (SANTOS; MORTIMER, 2001, p. 103). Dessa forma, essa pesquisa propõe a discussão e a reflexão do tema "atividade mineradora em MG", a partir das leituras do ocorrido nas cidades de Mariana e Brumadinho.

Para dar suporte para essas discussões, aproximo-me da vertente teórica da Ciência, Tecnologia e Sociedade (CTS), principalmente com os trabalhos de Wildson Santos. Segundo o pesquisador, o movimento CTS surge em contraposição ao cientificismo, que valoriza a ciência por si mesmo, depositando uma crença cega em seus resultados positivos. Logo, o objetivo do Ensino de Ciências nessa perspectiva é preparar os estudantes para o exercício da cidadania.

Pensar em formação cidadã a partir dos pressupostos da corrente CTS me faz refletir sobre a aparente neutralidade dos discursos que circundam no processo de desenvolvimento científico e tecnológico. Segundo o referencial teórico e metodológico da Análise de Discurso de Linha Francesa (AD), os discursos de um sujeito são marcados pela historicidade, situado no contexto sócio-histórico de uma comunidade, num tempo e

20 conceito de tomada de decisão se ancora no trabalho de Santos e Mortimer (2001). 


\section{Q1:-Mosicas}

DOI: $10.12957 / \mathrm{e}-\mathrm{mosaicos} .2021 .45864$

espaço concretos, ou seja, é constituído socialmente, trazendo consigo suas histórias de vida e de leitura (ORLANDI, 2012).

É um sujeito interpelado pela ideologia, sua fala reflete os valores, as crenças de um grupo social. Não é único, mas divide o espaço de seu discurso com o outro, na medida em que, na atividade enunciativa, orienta, planeja, ajusta sua fala tendo em vista um interlocutor real, e também porque dialoga com a fala de outros sujeitos, de outros momentos históricos, em um nível interdiscursivo (BRANDÃO, 2012, p. 26).

Desse modo, não existem sentidos únicos e prontos por detrás de um discurso, e sim um processo de produção de sentidos que nega a sua aparente transparência e existência de um sujeito "neutro" (ORLANDI, 2012).

São essas duas frentes (CTS e AD) que me auxiliam no trabalho com o caso simulado no âmbito da formação inicial de professores de Química. A corrente CTS aponta caminhos para a tomada de decisão pelos cidadãos. Já a $A D$ mostra que não há neutralidade nos diferentes discursos, sendo cada sujeito influenciado por suas histórias de leituras e de vida.

Nesse contexto, tenho como objetivo no presente artigo investigar algumas dificuldades e potencialidades encontradas pelos licenciandos em Química, ao vivenciarem a construção e a execução de um caso simulado.

\section{As CONDIÇõES DE PRODUÇÃo E OS CAMINHOS METOdOLÓGICOS DA PESQUISA}

Esta é uma pesquisa com abordagem qualitativa sustentada pelo referencial da $A D$. Esse referencial é contrário à visão empirista da ciência, pressupondo um objeto estático, tendo uma única verdade que será descoberta após a sistematização e a coleta de dados. As construções metodológicas e analíticas compreendem o posicionamento em determinado lugar, não neutro, pois não segue critérios empíricos (positivistas). Essa não neutralidade "baseia-se no fato de que, nesse movimento de construção do corpus, há um posicionamento teórico declarado. É importante não a confundir com alguma forma de "coleta de dados" levada a cabo de forma displicente ou não comprometida" (FLÔR, 2009, p. 98).

Compreendo, também, a partir dessa perspectiva, que as condições de produção englobam os sujeitos e a situação (estrito e amplo). Em relação às condições de produção, "em um sentido estrito temos as circunstâncias da enunciação: é o contexto imediato. $E$ se as consideramos em sentido amplo, as condições de produção incluem o contexto 
DOI: $10.12957 / \mathrm{e}-\mathrm{mosaicos} .2021 .45864$

sócio-histórico, ideológico" (ORLANDI, 2012, p. 30). Apesar dessa distinção para fins de explicação, na prática não é possível dissociar um do outro, "em todas as situações de linguagem esses contextos funcionam conjuntamente" (ORLANDI, 2015, p. 17). Diante disso, é de fundamental importância estabelecer algumas das condições de produção dessa pesquisa.

O curso de Química - grau acadêmico Licenciatura - da Universidade Federal de São João del-Rei (UFSJ) tem a duração de quatro anos, iniciando os componentes curriculares de formação específica já no primeiro período. O componente curricular em que essa pesquisa se insere está alocado no sétimo período do curso, intitulado como Química e Sociedade e apresenta os seguintes objetivos:

Compreender as discussões teóricas da vertente CTSA a partir da literatura da área; Identificar as potencialidades e desafios da inserção de temas sociais em aulas de Química; Questionar o papel da mídia e dos textos de divulgação científica; Incentivar intervenções em aulas de Química a partir dos fundamentos teóricos estudados (BRASIL, 2018, p. 84).

Esse é um componente curricular com carga horária total de 54 horas (18 horas teóricas e 36 horas práticas), tendo encontros semanais com duração de 3 horas. Ao longo dos encontros presenciais, diferentes textos e atividades foram pensados na tentativa de atingir aos objetivos propostos. Dentre as ações, no primeiro semestre letivo de 2019, os 12 estudantes ${ }^{3,}$ devidamente, matriculados nesse componente curricular, vivenciaram uma atividade avaliativa, intitulada de caso simulado, sendo essa o objeto de estudo deste artigo.

Para facilitar a compreensão em torno da construção e da execução do caso simulado, divido essa apresentação em três momentos, sendo o primeiro momento, a organização do caso simulado; o segundo referente à aplicação do caso simulado e o terceiro, a avaliação da atividade. Os aspectos metodológicos desta pesquisa vão ao encontro dos caminhos apresentados por Flôr (2007), que indica algumas estratégias para utilização de um caso simulado CTS.

\section{A) Construção do CASO Simulado}

Ao longo dos seis encontros iniciais (Aulas de 1 a 6 ) presenciais do componente curricular, diferentes leituras, discussões e atividades foram propostas em torno da

3 Para a participação dos estudantes na pesquisa, foram recolhidas as devidas autorizações por meio do Termo de Consentimento Livre e Esclarecido.

O CASO SIMULADO CTS NA FORMAÇÃO INICIAL DE PROFESSORES DE QUIIMICA: UM ESTUDO DO ROMPIMENTO DA BARRAGEM 
DOI: $10.12957 / \mathrm{e}-\mathrm{mosaicos} .2021 .45864$

perspectiva CTS, conforme pode ser visto no Qudro 1. Nesse momento, não houve a apresentação da proposta do caso simulado, tendo como objetivo fundamentar e fomentar diferentes olhares para questões sociais articuladas à Ciência e à Tecnologia.

Quadro 1: síntese das leituras e atividades desenvolvidas.

\begin{tabular}{|c|c|}
\hline AULAS & ATIVIDADES DESENVOLVIDAS \\
\hline 1 a 6 & $\begin{array}{l}\text { - Leituras e discussões em torno de diferentes artigos (AULER; BAZZO, 2001; } \\
\text { CARNIO, 2012; MARTÍNEZ-PÉREZ, 2012; PAVÃO; FREITAS, 2011; SANTOS; } \\
\text { MORTIMER, 2001). } \\
\text { - Leitura e análise do filme "Saneamento Básico, o filme" de } 2007 \text { e da música } \\
\text { Another Brick in the Wall - Pink Floyd. } \\
\text { - Algumas atividades desenvolvidas: Análise de livros didáticos a partir da } \\
\text { perspectiva CTS; Investigação sobre os diferentes discursos produzidos pela } \\
\text { mídia; Levantamento e análise de temas controversos, tais como: } \\
\text { desenvolvimento de bombas nucleares, clonagem, agrotóxicos, exploração de } \\
\text { minério, uso medicinal da maconha e a "pílula do câncer" (Fosfoetanolamina). }\end{array}$ \\
\hline 7 & $\begin{array}{l}\text { - Para aprofundar em torno do tema gerador (Rompimento da Barragem em } \\
\text { Brumadinho-MG), cada aluno teve que selecionar e apresentar ao grupo uma } \\
\text { notícia. Os principais pontos abordados foram em torno da dependência } \\
\text { econômica das atividades mineradoras pelo estado de MG, devastação ambiental, } \\
\text { impactos positivos e negativos para a comunidade local e regional, aspectos } \\
\text { geográficos e características físico-químicas dos rejeitos de mineiro. Ao final da } \\
\text { discussão, chegamos à questão problema: } \\
\text { Rompimento da Barragem em brumadinho: Acidente ou crime ambiental? } \\
\text { - Organização do caso simulado a partir da leitura do artigo de Flôr (2007), } \\
\text { englobando os elementos: seleção dos problemas, definição da rede de atores e } \\
\text { elaboração da documentação. }\end{array}$ \\
\hline 8 a 11 & - Sem encontros presenciais - organização do caso simulado \\
\hline 12 & - Execução do caso simulado \\
\hline 13 & - Roda de conversas: avaliação do caso simulado \\
\hline
\end{tabular}

Fonte: elaborado pelo autor.

A partir da fundamentação teórica e das análises de diferentes temas, iniciou-se o processo de construção do caso simulado. Para o encontro de número 7 , foi sugerida a leitura do artigo de Flôr (2007) e a apresentação de uma notícia sobre o rompimento da barragem em Brumadinho - MG por cada estudante. Tendo o professor do componente 
DOI: $10.12957 / \mathrm{e}-\mathrm{mosaicos} .2021 .45864$

curricular como mediador do processo de discussão, diferentes questões foram levantadas, dentre elas:

A mineração é importante? Quais os impactos socioeconômicos da diminuição da mineração no estado de MG? Há impactos na saúde dos mineradores e comunidade local? Qual a lógica mercantil na atividade mineradora? Qual o histórico da barragem do fundão (Mariana)? O que aprendemos ou deixamos de aprender com o desastre de BrumadinhoMG? Qual a concentração de minério de ferro nas reservas mundiais e em MG?

A definição desse tema teve origem após longas discussões nas aulas de 1 a 6 , sendo também amplamente apresentado e discutido na mídia local no período em que a disciplina foi iniciada. Portanto, o tema apresenta um significado real para os alunos dessa pesquisa.

Partindo das questões apresentadas, entendo que o professor deve, além de simular condições concretas nas quais se desenvolve uma controvérsia, procurar definir o papel dos atores participantes (FLÔR, 2007). Nesse caso, a controvérsia se deu em torno da seguinte questão:

\section{ROMPIMENTO DA BARRAGEM EM BRUMADINHO: ACIDENTE OU CRIME AMBIENTAL?}

Com relação à definição da rede de atores para a participação no caso simulado, tal como orienta Flôr (2007), "esses papéis devem ser verossímeis e com posturas favoráveis e desfavoráveis colocadas de forma equilibrada, além de especialistas e mediadores" ( $p$. $3)$.

Sendo assim, quatro equipes/atores foram elaboradas:

1 Samarco: Empresa mineradora atuante em diferentes estados do Brasil; para o caso simulado, o interesse está no rompimento da Mina do Córrego do Feijão e na cidade afetada em Brumadinho-MG.

2 Governo: Órgão responsável pela fiscalização das atividades mineradoras de MG.

3 Associação de moradores: os moradores de Brumadinho, ao sofrerem as consequências do rompimento da barragem, se unem e buscam soluções ao participar das discussões.

4 Ambientalistas: Grupo de pesquisadores não governamental, esses são chamados para o debate com o intuito de apontar os impactos das atividades mineradoras em MG. 
DOI: $10.12957 / \mathrm{e}-\mathrm{mosaicos} .2021 .45864$

Como etapa final da organização do caso simulado, 3 aulas foram concedidas para os grupos no intento de elaborar as questões e a documentação referente ao tema. Nesse período sem encontros presenciais, reuniões entre o professor e os grupos foram realizadas.

\section{B) EXECUÇÃO dO CASO SIMULADO}

Após o período de estudos e de planejamento do caso simulado, iniciou-se a execução da atividade. De início, as quatro equipes foram separadas nos extremos da sala de aula. Com os grupos formados, o docente apresentou os critérios adotados para o caso simulado, sendo eles:

$1^{\text {a }}$ etapa - Apresentação dos grupos: a partir de um sorteio prévio para definir a ordem de apresentação. Cada equipe teve 6 minutos para responder: "quem são vocês?". Ou seja, quais personagens sociais os grupos estão representando neste caso simulado. Para isso, as quatro equipes, por meio de vídeos, gráficos e imagens se apresentaram, defendendo os seus principais argumentos. (Tempo total: 24 minutos)

$2^{a}$ etapa - Primeira rodada de perguntas e respostas: para essa dinâmica, cada equipe teve a oportunidade de elaborar uma pergunta para outro grupo com direito a resposta, réplica e tréplica. Seguindo o sorteio realizado na etapa anterior, cada equipe pode escolher para quem questionar. Nessa dinâmica, quatro rodadas foram feitas e o tempo máximo era de até 1 minuto para pergunta, 1,5 minuto para resposta e 1 minuto para réplica e tréplica. (Tempo total: 18 minutos)

$3^{a}$ etapa - Segunda rodada de perguntas e respostas: há duas diferenças dessa etapa para a anterior, sendo elas: foram sorteados quem pergunta e quem responde e não houve direito à tréplica. Essa etapa ocorreu em dois momentos consecutivos. (Tempo total: 28 minutos)

- Intervalo de 10 minutos para construção dos argumentos finais.

$4^{a}$ etapa - Considerações finais: cada equipe teve aproximadamente 4 minutos para apresentar os principais elementos a partir do discutido no caso simulado. (Tempo total: 16 minutos)

Do ponto de vista teórico, a atividade deveria durar aproximadamente 1,5 hora. Entretanto, em alguns momentos de pergunta e resposta, os grupos pediram 30 segundos para dialogar com a equipe antes da resposta. Nesse sentido, a atividade durou em torno de 2 horas. Após a $4^{\mathrm{a}}$ etapa, os licenciandos foram liberados e a discussão dessa atividade ficou marcada para o próximo encontro presencial da disciplina (aula 13). 
DOI: $10.12957 / \mathrm{e}-\mathrm{mosaicos} .2021 .45864$

\section{C) AVALIAÇÃo do CASO SIMULADO: CONSTRUINDO O CORPUS DE ANÁLISE}

Como etapa final do caso simulado, foi realizada uma roda de conversas com o intuito de compreender as influências das atividades desenvolvidas e os caminhos trilhados pelos estudantes. Segundo Silva e Bernardes (2007),

A roda de conversas é um meio profícuo de coletar informações, esclarecer ideias e posições, discutir temas emergentes e/ou polêmicos. Caracterizase como uma oportunidade de aprendizagem e de exploração de argumentos, sem a exigência de elaborações conclusivas. A conversa desenvolve-se num clima de informalidade, criando possibilidades de elaborações provocadas por falas e indagações (p.54).

A partir disso, o corpus de análise se constitui a partir das falas dos estudantes na roda de conversas. Penso que todos esses dizeres dos estudantes se constituem como um texto, sendo este "[...] a unidade que 0 analista tem diante de si e da qual ele parte. [...]? Ele o remete imediatamente a um discurso que, por sua vez, se explicita em suas regularidades pela sua referência a uma ou outra formação discursiva" (ORLANDI, 2012, p. 63). O conjunto formado por esses textos remeterá aos seus discursos sobre as potencialidades e os desafios das atividades desenvolvidas.

A análise é um processo que começa pelo próprio estabelecimento do corpus e que se organiza face à natureza do material e à pergunta (ponto de vista) que o organiza. Daí a necessidade de que teoria intervenha a todo momento para "reger" a relação do analista com o seu objeto, com os sentidos, com ele mesmo, com a interpretação (p. 64).

Partindo do objetivo apresentado, compreendo a importância de delimitar o corpus a partir das condições de produção, sendo essas delimitadas, principalmente, pelas leituras e pelas discussões realizadas em sala de aula, tal como apresentadas e sintetizadas no Quadro 1.

Finalizada a roda de conversas, as falas dos estudantes foram transcritas e utilizados nomes fictícios escolhidos pelo pesquisador. De posse das transcrições, tendo em vista o objetivo e as condições de produção em sentido estrito e amplo, realizei a leitura do texto em diversos momentos, na busca de "de-superficializá-lo", como destaca Orlandi (2012): 
DOI: $10.12957 / \mathrm{e}-\mathrm{mosaicos} .2021 .45864$

Há uma passagem inicial fundamental que é a que se faz entre a superfície linguística (o material de linguagem bruto coletado, tal como existe) e objeto discursivo, este sendo definido pelo fato de que o corpus já recebeu um primeiro tratamento de análise superficial, feito em uma primeira instância, pelo analista, e já se encontra de-superficializado (p. 65).

Partindo desse processo de "de-superficialização" do texto produzido na roda de conversas, uma categoria analítica emergiu, tal como será apresentada a seguir.

Cabe ressaltar que, em virtude do número de alunos participantes da roda de conversas, optei por não expor recortes de falas de todos os sujeitos, com receio de cair em repetição e/ou superficialidade da discussão. Por isso, serão apresentadas as falas significativas que representam a concordância pelo coletivo e que englobe ao menos cada um dos grupos do subitem $b$.

\section{O CASO SIMULADO: COM A PALAVRA, OS LICENCIANDOS}

A partir das transcrições realizadas da roda de conversas, diferentes posicionamentos se destacam acerca do caso simulado. Em um ponto específico da discussão o pesquisador questionou:

Como foi a experiência de construir e vivenciar um caso simulado?

A primeira a responder foi a aluna Letícia, que disse:

Foi uma surpresa muito grande, porque sinceramente, é... principalmente para mim que fiquei com a Vale, tudo que eu não queria era ficar com ela. Então assim, eu não queria fazer aquilo, eu tinha raiva quando lia as coisas. As mesmas angústias que eu ouvia os colegas falando durante $o$ caso simulado, foi a mesma que senti quando lia os materiais. Eu fiquei muito agoniada, mas foi bom. Quando estava ali foi tão legal, eu aprendi tanto. Eu até comecei a entender os argumentos da empresa".

É interessante perceber na fala da acadêmica o seu conflito em ter que defender os discursos de um grupo de atores com o qual ela não concorda. Para Flôr (2007), "talvez seja mais produtivo para os educandos, que deverão procurar argumentos para contrariar algo que a princípio defendiam, crescendo assim em sua capacidade crítica e visão global do problema" (p. 4). Esse argumento se aproxima do dito pela estudante quando é dito que "eu até comecei a entender os argumentos da empresa". 
DOI: $10.12957 / \mathrm{e}-\mathrm{mosaicos} .2021 .45864$

O fato de situarmos a formação discursiva na qual determinado discurso é originário restringe os sentidos, facilitando o direcionamento da interpretação (ORLANDI, 2012). Portanto, ao deslocar o sujeito para a formação discursiva que rodeia a empresa Samarco, mesmo não concordando com os argumentos, fez com que a estudante compreendesse os discursos produzidos.

Outra característica marcante na fala da estudante são os sentimentos negativos produzidos (surpresa, angústia, agoniada e raiva) durante o processo de construção do caso simulado. Esses sentimentos estão alinhados com o fato de ela não concordar com os argumentos da empresa. Entretanto, durante a execução do caso simulado, ela aponta que o processo foi "legal" e que houve bastante aprendizado.

Podemos dizer então que, para a estudante Letícia, passar por essa experiência gerou aprendizagens, possibilitando um olhar mais abrangente para o tema, enxergando-o a partir de diferentes pontos de vista. Dessa forma, esse processo pode auxiliar o futuro professor/cidadão a tomar decisões mais conscientes.

\begin{abstract}
Assim, uma pessoa funcionalmente letrada em ciência e tecnologia saberia, por exemplo, preparar adequadamente diluições de produtos; compreender satisfatoriamente as especificações de uma bula de um medicamento; adotar profilaxia para evitar doenças básicas que afetam a saúde pública; exigir que as mercadorias atendam às exigências legais de comercialização, como especificação de sua data de validade, cuidados técnicos de manuseio, indicação dos componentes ativos; operar produtos eletroeletrônicos etc. Além disso, essa pessoa saberia posicionar-se, por exemplo, em uma assembleia comunitária para encaminhar providências junto aos órgãos públicos sobre problemas que afetam a sua comunidade em termos de ciência e tecnologia (SANTOS, 2001, p. 480).
\end{abstract}

Já para a estudante Carol, "a minha maior dificuldade foi encontrar fontes confiáveis. Tinha muita informação também que não é clara, sabe? Por isso que não dá para confiar na primeira notícia que a gente encontra". Esse fenômeno se agrava, principalmente, com o advento da Ciência e Tecnologia, devido à praticidade e à velocidade que os textos digitais oferecem. Conforme discutem Santos e Vieira Júnior (2019) ao apresentar o trabalho de Brites, Amaral e Catarino (2018), a era da pós-verdade e a veiculação de notícias falsas chamam atenção para um grande problema: a falta da verificação da veracidade das notícias disponibilizadas em domínio público. 
DOI: $10.12957 / \mathrm{e}-\mathrm{mosaicos} .2021 .45864$

Isso afeta diretamente a escola, visto que os estudantes realizam pesquisas corriqueiramente, mas nem sempre verificam as fontes consultadas, propiciando a cultura da falta de leitura crítica e reflexiva, além de propagar notícias de caráter duvidoso que não contribuem para a sua formação como cidadãos conscientes (SANTOS, VIEIRA JÚNIOR, 2019, p. 2).

Nesse contexto, o (futuro) professor deve saber identificar e orientar seus estudantes sobre as notícias falsas em torno do tema de interesse. Além disso, perceber que há "muita informação também que não é clara" é entender que a linguagem é opaca, sendo necessário pensar a linguagem como uma interação que possibilita interpretações, tanto do escritor quanto do leitor (ORLANDI, 2012).

Ainda para a estudante Carol, no processo de construção do caso simulado, houve a "dificuldade em formular perguntas, tendo que pensar sobre o que virá de resposta". Essa situação mostra o desafio ao adentrar no jogo discursivo, sendo regulado pelo mecanismo de antecipação. Para a pesquisadora Orlandi (2012), "segundo o mecanismo de antecipação, todo sujeito tem a capacidade de experimentar, ou melhor, de se colocar no lugar em que o seu interlocutor "ouve" suas palavras. Ele antecipa-se assim a seu interlocutor quanto ao sentido que suas palavras produzem" (ORLANDI, 2012, p. 39).

Essa ação de se colocar na posição do interlocutor, buscando delimitar os sentidos produzidos para o seu discurso é essencial no ambiente escolar. Apesar de não termos o total controle disso, perceber o contexto e algumas das histórias de leituras do interlocutor/estudante pode facilitar o processo de ensino e aprendizagem.

Em concordância com os argumentos da Carol, a acadêmica Natália, pertencente ao grupo do Governo, diz que: "os argumentos eram todos pensados em dinheiro, como se uma vida pudesse ser substituída por isso". Tal consideração reflete um dos impactos do desenvolvimento desenfreado da tecnologia, como podemos ver na fala de Santos e Mortimer (2001).

O desenvolvimento tecnológico tem ocorrido de maneira desordenada, sobretudo ao atender muito mais os interesses de mercado do que as reais necessidades humanas. O desenvolvimento científico e tecnológico tem exercido uma poderosa influência sobre o comportamento humano. Os hábitos de consumo, as relações humanas, o modo de vida, as relações de trabalho, as crenças e valores são cada vez mais resultantes de demandas do desenvolvimento tecnológico (p. 102). 
DOI: $10.12957 /$ e-mosaicos.2021.45864

Esse posicionamento da discente mostra também uma preocupação humanística sobre o desenvolvimento científico e tecnológico, colocando o sujeito não em posição de inferioridade frente a esse processo, no caso, o potencial econômico não deve predominar frente as decisões.

Em consonância, o estudante Lucas fala que "mas é bom enxergar isso, pois mostra como a ciência está sempre articulada aos interesses econômicos". Assim como o dito por Carol, é preciso perceber essa articulação e identificar a ciência como uma atividade não neutra, tendo o seu desenvolvimento articulado nos aspectos políticos, econômicos, culturais e ambientais.

As falas de Carol e Lucas são de fundamental importância quando pensadas no contexto de formação de professores, uma vez que se espera que esses futuros docentes tenham em mente os riscos que podem gerar quando o Ensino de Ciências é orientado por uma visão carregada de mitos, crenças e ideias do senso comum sobre a ciência, tecnologia e o cientista (FREITAS, 2011).

Ao longo da roda de conversas, foi possível identificar outras falas dos alunos sobre como participar desse processo auxiliou em sua formação. Por exemplo,

"aprendi a argumentar" (Lucas)
"me ajudou a me soltar" (Carol)
"ter que responder algo que não esperava, sabe?" (Letícia)

É possível perceber nessas falas a relevância do caso simulado para fomentar a argumentação. Sobre a argumentação Santos e Mortimer (2001) discutem que

Diversos estudos têm demonstrado a importância da argumentação no processo de tomada de decisão, evidenciando a necessidade de ela ser melhor desenvolvida para propiciar uma boa capacidade de tomada de decisão. Patronis, Potari e Spiliotopoulou (1999) consideram a argumentação como um processo social, no qual indivíduos em cooperação tentam ajustar suas intenções e interpretações por uma apresentação verbal de uma razão para as suas ações. Para eles, esse processo é fundamental para uma formação mais crítica do cidadão (p. 106). 
DOI: $10.12957 / \mathrm{e}-\mathrm{mosaicos} .2021 .45864$

Por meio de processos argumentativos em que ocorrem questionamentos, os estudantes podem ressignificar seus argumentos, apontando para uma posição mais coerente e que leve em conta outros pontos de vista.

Após destacar a potencialidade do caso simulado ao promover interações argumentativas, apresento a fala de Lucas que diz que "quando o caso simulado começa a ficar bom o tempo acaba". Apesar dessa atividade ter durado 2 horas, ressalto a necessidade de mais tempo para tal. No decorrer do processo, os alunos começam a ter uma participação mais ativa, se envolvendo e querendo trazer novos dados e questões para debate. Apesar disso, conforme pode ser visto na fala de Letícia, a discussão do caso simulado se estendeu para além da sala de aula, possibilitando novas discussões e reflexões.

"Eu não queria parar, quando sai do caso simulado eu comentei com o Mateus e ficamos conversando horas aquilo" (Letícia).

As falas apresentadas neste tópico nos mostram algumas dificuldades e potencialidades ao se trabalhar com o caso simulado em uma perspectiva CTS. Além disso, enquanto professor e pesquisador desse processo, percebo que essa atividade possibilitou aumentar a autoestima dos alunos, uma vez que eles veem seus argumentos valorizados; fomentar a tomada de decisões ao colocar os sujeitos em confronto com seus argumentos; a articulação entre os eixos da Ciência, Tecnologia e Sociedade. Enfim, deslocou o professor da posição de detentor de conhecimento e o estudante como sujeito passivo e sem histórias de leituras e de vida.

\section{CONSIDERAÇõES FINAIS}

Entendo que o júri simulado, diferentemente do caso simulado, possibilita um grupo "vitorioso" ao final da dinâmica, corroborando com a visão de que há uma verdade única que precisa ser descoberta. Ou seja, implica na resolução de problemas que envolvem a escolha entre um e outro. Ao contrário disso, o caso simulado, ao trabalhar com temas sociocientíficos controversos, fomenta a capacidade de expressar ideias e argumentos. Nesse processo, os diferentes sujeitos, ao avaliarem as opiniões que surgem, tomam decisões mais conscientes, superando a visão de alternativas dicotômicas sobre o problema.

Apesar disso, pensando na esfera educacional, o caso simulado deve ser apenas uma das diferentes ações dentro de um planejamento maior, com o objetivo de formação 
DOI: $10.12957 / \mathrm{e}-\mathrm{mosaicos} .2021 .45864$

para cidadania. Nesse contexto mais amplo, o ensino deve ir além da memorização e da reprodução de conceitos e de fórmulas, indo no sentido de uma educação social responsável, com formação de valores e atitudes.

\section{REFERÊNCIAS}

AULER, D.; BAZZO, W. A. Reflexões para a implementação do movimento CTS no contexto educacional brasileiro. Ciência \& Educação, v.7, n.1, p.1-13, 2001.

BRANDÃO, H. N. Enunciação e construção do sentido. São Paulo: Contexto, 2012.

BRASIL. Projeto Pedagógico do Curso de Licenciatura em Química. Universidade Federal de São João del-Rei. São João del-Rei, 2018.

CARNIO, M. P. O significado atribuído por licenciandos ao currículo de Biologia numa perspectiva CTSA. Dissertação (Mestrado em Educação para Ciência). Faculdade de Ciências, Universidade Estadual Paulista, Bauru - SP, 2012.

FLÔR, C. C. Leitura e formação de leitores em aulas de química no ensino médio. Tese de doutorado. PPGECT/UFSC. 2009.

. Possibilidades de um caso simulado CTS na discussão da poluição ambiental. Ciência \& Ensino, vol. 1, número especial, 2007.

FREITAS, D. A perspectiva curricular Ciência, Tecnologia e Sociedade - CTS - no ensino de ciência. In. PAVÃO, A. C.; de FREITAS, D. Quanta ciência há no Ensino de Ciências. São Carlos: EdUFSCar, 2011.

LANA, Z. M. de O. A atividade mineradora em minas gerais e em ouro preto: impactos socioambientais e intervenções para a sustentabilidade. Sociedade e Território, v. 27, n. 3, p. 45-59, 2015.

MARTÍNEZ-PÉREZ, L. F. Questões sociocientíficas na prática docente - Ideologia, autonomia e formação de professores. São Paulo: UNESP, p. 55-62, 2012.

ORLANDI, E.P. Análise de Discurso: princípios e procedimentos. 10.ed. Campinas, Pontes Editores, 2012.

. Análise de Discurso. In: ORLANDI, E. P; LAGAZZI-RODRIGUES, S. (org.) Discurso e textualidade, Campinas: PONTES, 2015, p. $13-35$. 
DOI: $10.12957 /$ e-mosaicos.2021.45864

PASSOS, F. L., COELHO, P., DIAS, A. (Des)territórios da mineração: planejamento territorial a partir do rompimento em Mariana, MG. Cad. Metrop., v. 19, n. 38, p. 269-297, 2017.

PAVÃO, A. C.; de FREITAS, D. (orgs). Quanta ciência há no Ensino de Ciências. São Carlos: EdUFSCar, 2011.

SANTOS, W. L. P.; MORTIMER, E. F. Tomada de decisão para ação social responsável no Ensino de Ciências. Ciência \& Educação, v.7, n.1, p.95-111, 2001.

SANTOS, M. J.; VIEIRA JÚNIOR, N. Repercussões das fake news na educação em Ciências: estímulo ao pensamento crítico e reflexivo no Ensino Fundamental II. Educação Básica Revista. vol.4, n.13, 2019.

SILVA, P. B. G.; BERNARDES, N. M. G. Roda de conversas - Excelência acadêmica é a diversidade. Revista Educação. n. 1, v. 61, p. 53-92, 2007.

Recebido em 08 de outubro de 2019 Aceito em 17 de março de 2021

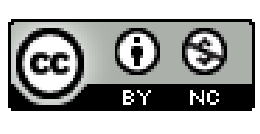

A e-Mosaicos Revista Multidisciplinar de Ensino, Pesquisa, Extensão e Cultura do Instituto de Aplicação Fernando Rodrigues da Silveira (CAp-UERJ) está disponibilizada sob uma Licença Creative Commons - Atribuição - NãoComercial 4.0 Internacional.

Os direitos autorais de todos os trabalhos publicados na revista pertencem ao(s) seu(s) autor(es) e coautor(es), com o direito de primeira publicação cedido à e-Mosaicos.

Os artigos publicados são de acesso público, de uso gratuito, com atribuição de autoria obrigatória, para aplicações de finalidade educacional e não-comercial, de acordo com o modelo de licenciamento Creative Commons adotado pela revista. 